\title{
Mitral valve replacement in the first three months of life
}

\author{
JAMES C POLLOCK, SAID SHAWKAT, ALAN HOUSTON \\ From the Departments of Cardiology and Cardiac Surgery, Royal Hospital for Sick Children, Yorkhill, Glasgow
}

SUMMARY Two infants, aged 2 and 3 months, underwent mitral valve replacement with Björk-Shiley mechanical valves for severe congenital mitral regurgitation not amenable to valve repair. Both infants survived the operation and left hospital taking a low dose aspirin anticoagulant regimen. One child survived for three years without incident, but the other died at 11 months of pneumonia after valve replacement for tissue ingrowth and subsequent thrombosis.

Every effort is made in children to conserve the native valve by reconstructive techniques since replacement in this group carries appreciable short and long term mortality and morbidity. ${ }^{1-4}$ Occasionally, conservation is impossible owing to severe valvar dysplasia. We report our experience with mitral valve replacement in two such infants with severe dysplastic mitral valves in the first three months of life.

\section{Patients and methods}

\section{CASE 1}

A 6 week old, full term male infant presented with failure to thrive, progressive tachycardia, and tachypnoea such that he required ventilation shortly after admission. Initial examination showed congestive heart failure and cardiomegaly on a chest radiograph (Fig. a). An apical systolic murmur was present. The initial diagnosis was of pneumonia and a small ventricular septal defect. Nevertheless, the infant could not be weaned from ventilatory support over a two week period, and his haemodynamic status gradually deteriorated despite digitalisation, fluid restriction, and vigorous diuretic treatment. The infant then underwent cardiac catheterisation, which showed gross mitral regurgitation with a mean left atrial pressure of $22 \mathrm{~mm} \mathrm{Hg}$ and "a" and " $v$ " wave pressures of 22 and $31 \mathrm{~mm} \mathrm{Hg}$ respectively.

The child underwent surgery, and the mitral valve was found to have rudimentary cusp tissue and very short attenuated chordae attached to two normally located papillary muscles. Under deep hypothermic

Requests for reprints to Mr J C Pollock, FRCS, Department of Cardiac Surgery, Royal Hospital for Sick Children, Yorkhill, Glasgow G3 8SJ.

Accepted for publication 17 July 1984

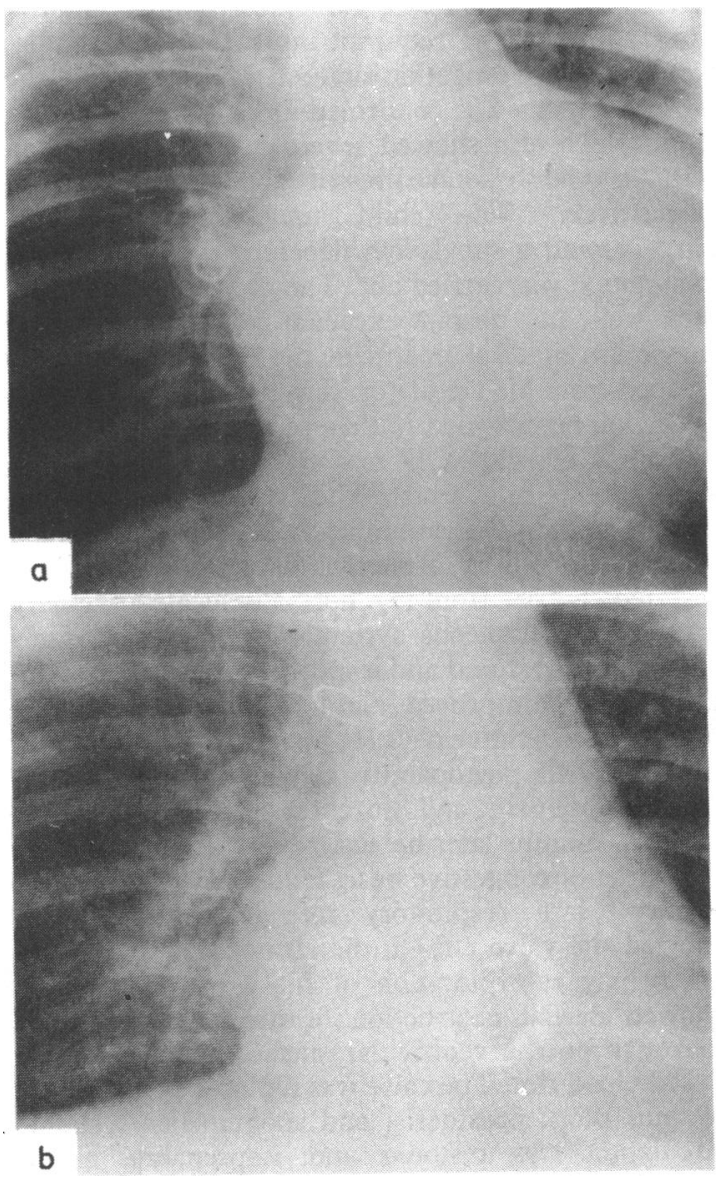

Fig. Case 1: chest radiographs (a) before and (b) three weeks afier mitral valve replacement. 
circulatory arrest for $\mathbf{2 0}$ minutes, the largest valve that the annulus would take, a $19 \mathrm{~mm}$ Björk-Shiley prosthesis was implanted.

Spontaneous systemic circulation was restored and a low dose infusion of isoprenaline given. The infusion was discontinued within 12 hours, and the child was extubated on the third postoperative day. Congestive heart failure rapidly resolved with diuretic treatment and the child was discharged on the twentieth postoperative day in sinus rhythm taking $30 \mathrm{mg}$ of aspirin daily and frusemide. A chest radiograph on discharge showed pronounced resolution of his cardiomegaly (Fig. $b$ ). Three years later the child had grown normally and was taking only low doses of aspirin.

\section{CASE 2}

A full term male infant was admitted seven weeks after birth in severe congestive heart failure. Shortly after admission he required intubation and ventilation. Initial investigation suggested coarctation of the aorta, and this was confirmed at cardiac catheterisation, which also showed severe mitral regurgitation with " $a$ " and " $v$ " wave pressures of 23 and $34 \mathrm{~mm} \mathrm{Hg}$ respectively. The child underwent immediate surgery, and a subclavian flap repair of a preductal coarctation was carried out. The procedure was tolerated well, but despite excellent femoral pulses and maximum medical treatment the child could not be weaned from his ventilator. Two weeks after his first operation he returned to theatre and the mitral valve was replaced with a $17 \mathrm{~mm}$ Björk prosthesis under deep hypothermic arrest. The anterior leaflet was an opaque immobile membrane, and the posterior cusp was represented by fibrous nodules into which were inserted chordae from two normally located papillary muscles. Spontaneous systemic circulation in sinus rhythm was restored and isoprenaline given. His condition rapidly improved, and he was extubated on the fourth postoperative day. He was discharged home on the nineteenth postoperative day taking $30 \mathrm{~m}$ of aspirin daily, digoxin, and diuretics.

Seven months later he again presented with a sudden onset of congestive heart failure after a three dáy history of a respiratory infection. Examination showed the valve click to be absent. He underwent emergency re-exploration of his prosthesis, which showed partial obstruction of the valve by tissue ingrowth on the ventricular surface and a superimposed blood clot. The valve was replaced with another $17 \mathrm{~mm}$ Björk prosthesis; and spontaneous systemic circulation was restored and isoprenaline given. Repeated attempts to reduce his ventilatory support were defeated by poor gas exchange, and despite massive antibiotic treatment he died three weeks post- operatively of bilateral bronchopneumonia. Necropsy showed that the replacement prosthesis was functioning satisfactorily.

\section{Discussion}

Mitral valve replacement was undertaken as a life saving measure in two seriously ill infants. Both survived operation and left hospital, although one died within the first year of a prosthetic valve complication. Initially, both valves functioned well haemodynamically. Congestive heart failure rapidly resolved, and both children thrived despite the disproportionally large size of the new valves in these small hearts and the fact that both valves were of the old flat disc type.

The use of tissue valves in the left side of the heart has proved to be disappointing in children, especially those $<10$ years of age, owing to early degeneration and calcification. ${ }^{4}$ Hence in older children, mainly teenagers, we have routinely implanted mechanical valves in the left side and provided anticoagulation with warfarin. This policy has worked well; only one 14 year old child had to be given aspirin because of poor patient compliance with warfarin. Because of the difficulty in achieving anticoagulation control in the two infants in the present study, and since both were in sinus rhythm postoperatively, we gave low doses of aspirin in these cases. This regimen has been effective in a recent series of children ${ }^{5}$ with mechanical valves and seemed to be satisfactory in our two patients since neither had any embolic incidents.

Our second case illustrates how rapidly tissue ingrowth can occur in young children. Pannus formation producing valve dysfunction in the Björk prosthesis has been reported as early as one month after implantation. 6 Whether warfarin anticoagulation would have affected the clinical course of this case is doubtful. A recent report of 1400 mechanical valve replacements in adults comparing two types of valve suggests that the incidence of thromboembolism is significantly higher with the Biörk than with the St Jude hinged prosthesis, but this series included a large number of the older flat disc Björk prostheses. 7 The incidence of thrombosis with the Björk prosthesis may be reduced, firstly, by using the new Monostrut valve, which gives improved flow in the lesser orifice, and, secondly, by using carbonised sewing rings, which reduce the incidence of valve failure due to inhibition of tissue ingrowth.

These two infants show that mitral valve replace- $\cong$ ment is technically feasible as a life saving measure in the first months of life but that the very young patient appears especially prone to the complications of mechanical valves.

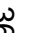
.

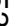
or s 。

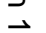

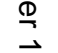

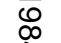
. 放 产 管 $\overrightarrow{0}$ 


\section{References}

1 Williams WG, Pollock JC, Geiss DM, Trusler GA, Fowler RS. Experience with aortic and mitral valve replacement in children. $\mathcal{F}$ Thorac Cardiovasc Surg 1981; 81: 326-33.

2 Dunn JM. Porcine valve durability in children. Ann Thorac Surg 1981; 32: 357-68.

3 Silver MM, Pollock JC, Silver MD, Williams WG, Trusler GA. Calcification in porcine xenograft valves in children. Am f Cardiol 1980; 45: 685-9.

4 Williams DB, Danielson GK, McGoon DC, Puga FJ, Mair DD, Edwards WD. Porcine heterograft valve replacement in children. $\mathcal{F}$ Thorac Cardiovasc Surg 1982;
84: 446-50.

5 Weinstein GS, Mavroudis C, Ebert PA. Preliminary experience with aspirin for anticoagulation in children with prosthetic cardiac valves. Ann Thorac Surg 1982; 33: 549-53.

6 Cleveland JC, Lebenson IM, Dague JR. Early postoperative development of aortic regurgitation related to Pannus ingrowth causing incomplete disc seating of a Björk-Shiley prosthesis. Ann Thorac Surg 1982; 33: 496-8.

7 Horstkotte D, Körfer R, Seipel L, Bircks W, Loogen F. Late complications in patients with Björk-Shiley and St. Jude medical heart valve replacement. Circulation 1984; 68 (suppl II): 175-84. 